\title{
DRIVERS OF ILLIQUIDITY IN THE ASEAN SOVEREIGN BOND MARKET
}

\author{
Harald Kinateder*, Robert Bauer**, and Niklas F. Wagner*** \\ *School of Business, Economics and Information Systems, University of Passau, Innstrasse 27, 94030 \\ Passau, Germany. Email: harald.kinateder@uni-passau.de \\ **School of Business, Economics and Information Systems, University of Passau, Innstrasse 27, 94030 \\ Passau, Germany. Email: robert-bauer2@gmx.de \\ ***School of Business, Economics and Information Systems, University of Passau, Innstrasse 27, 94030 \\ Passau, Germany. Email: niklas.wagner@uni-passau.de
}

\begin{abstract}
We study illiquidity in the ASEAN-5 sovereign bond markets from 2008 to 2019 by using an illiquidity measure, which is based on a proxy of the amount of arbitrage capital available in sovereign bond markets. Our analysis identifies three drivers of illiquidity in Singapore, namely economic policy uncertainty, the default spread and the gross domestic product (GDP) growth rate. In contrast, illiquidity of all other markets is mostly not characterized by economic drivers. It appears that overall liquidity is lower in the markets outside Singapore and therefore deviations in the yield curves are higher on average and arbitrage eliminates larger deviations not immediately but in a delayed manner.
\end{abstract}

Keywords: ASEAN-5 countries; Arbitrage capital; Illiquidity; Noise measure; Sovereign bond markets.

JEL Classifications: G12; G15.

Article history:

Received : March 14, 2020

Revised : November 6, 2020

Accepted : November 20, 2020

Available Online: December 31, 2020

https://doi.org/10.21098/bemp.v23i4.1453 


\section{INTRODUCTION}

Price deviations in the yield curve of the U.S. Treasury market are able to reflect liquidity of varying origins and magnitudes (Hu et al., 2013). However, the U.S. Treasury market is very unique in several dimensions, which distinguishes this bond market from others, like the Association of Southeast Asian Nations (ASEAN) sovereign bond markets. ${ }^{1}$ Therefore, additional research in other sovereign bond markets can provide new insights into liquidity and fixed-income arbitrage. In addition, it is important to understand the characteristics of bond liquidity as it is one of the major drivers of sovereign bond yields (Kinateder and Wagner, 2017). The ASEAN sovereign bond markets are geographically and economically different from the U.S., and there is a lack of research in the area of ASEAN bond liquidity (Tripathi et al., 2020), which motivates us to analyze how liquidity events transmit through price deviation in the yield curve outside the U.S.

In this paper, we use a bond market-specific illiquidity measure proposed by $\mathrm{Hu}$ et al. (2013) to study illiquidity in the ASEAN-5 sovereign fixed income markets. This illiquidity (noise) measure is based on the intuition that the level of illiquidity in fixed income markets and the arbitrage capital available in these markets are closely related. During tranquil periods, arbitrageurs usually have no shortage of capital, therefore, market prices are closer to their fundamental value as above average-price deviations are immediately corrected by arbitrageurs. In times of market stress, there is usually a lack of arbitrage capital as falling prices force arbitrageurs to provide additional funds or securities (e.g. due to a margin call), which can lead to significant differences between market prices and their fundamental values. Therefore, $\mathrm{Hu}$ et al. (2013) argue that transitory price deviations (the so-called "noise") in the bond market contain important information about how liquidity evolves over time in fixed income markets.

Our focus lies on the five founding countries of the ASEAN, namely Indonesia, Malaysia, the Philippines, Singapore, and Thailand. We first estimate monthly yield curves for each of the five ASEAN sovereign bond markets. Then, based on these results, we calculate the noise measure for each country's sovereign bond market. Finally, we apply a multiple time series regression using a comprehensive set of explanatory variables to identify the drivers of illiquidity in the ASEAN-5 sovereign bond markets. The country-specific explanatory variables include the country's local equity market return, the gold return in local currency, the Gross Domestic Product (GDP) growth rate and the inflation rate. In addition, we account for common explanatory variables, namely the corporate bond spread (as a proxy for the aggregate credit cycle), economic policy uncertainty, implied bond volatility, the steepness of the riskless Singapore term structure, and the Chicago Board Option Exchange (CBOE) Volatility Index (VIX).

Our results show that illiquidity conditions in Singapore's sovereign bond market follow our expectations, where noise (illiquidity) jumps during the global financial crisis and fluctuates on a very low level afterwards. In contrast, the

\footnotetext{
1 The U.S. market is one of the most liquid and the largest sovereign bond market in the world. In Q4 2019, the market size of the U.S. sovereign bond market was 19,710 billion USD compared to 816 billion USD in ASEAN-5 countries (Sources: Bank of International Settlement; Asian Development Bank).
} 
noise results of the other ASEAN-5 sovereign bond markets are characterized by a significant negative autocorrelation and mostly not by economic drivers. Moreover, noise in these bond markets is significantly higher during tranquil periods as compared to Singapore. The difference between Singapore and the remaining ASEAN-5 markets could be due to several reasons.

Firstly, Singapore has the strongest credit rating on sovereign bonds throughout the entire sample period and can, therefore, be treated as a safe haven. All other ASEAN-5 sovereign bond markets are rated weaker. As a result, there could be a flight-to-quality effect within the ASEAN-5 sovereign bond markets. Secondly, Singapore is a global financial centre and, thus, spill-overs from other financial centres, such as the U.S., affect this country more than other countries, which have a different economic focus. Thirdly, arbitrageurs also account for other factors than noise such as the basic level of liquidity. Lower basic liquidity in the ASEAN-5 markets outside Singapore as well as the lower credit rating of these markets might reduce the number of international arbitrageurs. Thus, a higher level of basic liquidity in Singapore's sovereign market could also explain why in tranquil periods small deviations in this yield curve are eliminated by arbitrage immediately, while there are a delayed reaction and higher yield curve deviations in the other markets.

Moreover, we identify three drivers of illiquidity for Singapore's sovereign bond market. The main driver is the corporate bond spread (as a proxy for the aggregate credit cycle), while at the same time an increase in economic policy uncertainty and declines in the aggregate business cycle (proxied by GDP growth rate), significantly drive sovereign bond illiquidity in Singapore. Our results also indicate that price deviations in Singapore's yield curve contain unique countryspecific information. Lastly, we find that our explanatory variables can explain illiquidity jumps during a market-wide illiquidity event but not the fluctuation of noise on a low level in tranquil periods.

This paper is related to the existing literature in several dimensions. First, it relates to the literature on how the amount of arbitrage capital in a specific market affects the effectiveness of arbitrage forces, or "limits of arbitrage", and possible price deviations (see e.g., Leland and Rubinstein 1988; Shleifer and Vishny, 1997; Gromb and Vayanos, 2002; Brunnermeier and Pedersen, 2009; Duffie, 2010). Musto et al. (2015) find a large and systematic mispricing during the global financial crisis between notes and bonds with identical cash flows. Mitchell and Pulvino (2012) provide a detailed and informative account of the financing of hedge funds during the global financial crisis and its potential implications for asset prices. More recently, Fleckenstein et al. (2014) document a large increase of mispricing between Treasury bonds and inflation-swapped Treasury inflation-protected securities during the 2008 global financial crisis. Second, the paper is related to the literature applying the noise measure of $\mathrm{Hu}$ et al. (2013) to sovereign bond markets as recommended by Durham (2015). Moinas et al. (2018) apply several illiquidity measures in a joint setting to the European sovereign bond market. Their empirical results show that market illiquidity shocks tighten funding constraints. For the Japanese sovereign bond market, Hattori (2019) documents a significant jump of noise during the global financial crisis, which provides some evidence that the illiquidity measure captures market-wide illiquidity shocks. Third, this paper is 
related to the literature identifying potential drivers of illiquidity (see e.g. Goyenko et al., 2011; Helwege et al., 2014; Adrian et al., 2017; Chung and Chuwonganant, 2018). Lastly, it is also related to the literature dealing with the relationship between sovereign bond yields and illiquidity (see e.g. Kinateder and Wagner, 2017; Kinateder et al., 2017). Our study contributes to this literature by thoroughly analysing illiquidity in the ASEAN-5 sovereign bond markets using a recently published liquidity proxy, which is explicitly designed for fixed-income markets. In addition, we not only focus on country-specific differences in illiquidity, but also study to which extent the respective bond market's illiquidity is related to various economic variables.

The remainder of the paper is organized as follows. Section II presents the methodology for curve fitting, estimating illiquidity (noise) and identifying drivers of illiquidity. Section III describes the sample data and contains the explanatory variables as well as a description of their theoretical relation to the illiquidity measure. Section IV conducts an analysis of the empirical results for curve fitting, noise and illiquidity drivers. Section $\mathrm{V}$ provides implications of our findings for investors. Finally, Section VI concludes.

\section{METHODOLOGY}

A. Construction of the Illiquidity Measure

The construction of the illiquidity measure is based on the approach of Hu et al. (2013). We calculate the illiquidity measure, Noise $_{j m^{\prime}}$ in country $j$ at month $m$ using the root mean square error:

$$
\text { Noise }_{j m}=\sqrt{\frac{1}{N_{j m}} \sum_{i=1}^{N_{j m}}\left[y_{i j m}-\hat{y}_{i j}\left(b_{j m}\right)\right]^{2}}
$$

where $N_{j m}$ is the number of government bonds available in country $j$ in month $m, y_{i j m}$ is the market yield of bond $i$, and $\hat{y}_{i j}\left(b_{i m}\right)$ is the respective model-implied yield of bond $i$ in country $j$ in month $m .^{2}$ We use the well-known Svensson (1994) approach to estimate the model-implied yield curve. ${ }^{3}$ Therefore, we have $b_{j m}=\left(\beta_{j m, 0^{\prime}} \beta_{j m, 1^{\prime}} \beta_{j m, 2^{\prime}} \beta_{j m, 3^{\prime}} \tau_{j m, 1^{\prime}} \tau_{j m, 2}\right)$, where $\beta_{j m, 0^{\prime}} \beta_{j m, 0}+\beta_{j m, 1^{\prime}} \tau_{j m, 1^{\prime}}$ and $\tau_{j m, 2}$ must be positive. The parameter vector $b$ of the Svensson (1994) approach is obtained by minimizing the weighted sum of squared deviations $\xi_{j m}$ between the model-implied and the empirically observable prices:

$$
\xi_{j m}=\min _{b_{j m}} \sum_{i=1}^{N_{j m}}\left[\left(\hat{P}_{i j}\left(b_{j m}\right)-P_{i j m}\right) \times D_{i j m}^{-1}\right]^{2},
$$

2 The market yield is calculated numerically based on the observed market prices and the future cash flows of the corresponding bond $i$ in country $j$ in month $m$.

3 Alternative methods may be applied. Lapshin (2019), for example, proposes a Bayesian nonparametric framework that addresses aspects of the shapes of yield curves including those of emerging markets. 
where $\hat{P}_{i j}\left(b_{j m}\right)$ denotes the model-implied price for bond $i$ in country $j$ in month $m, P_{i j m}$ is the observable market price of bond $i$ in country $j$ in month $m$, and $D_{i j m}$ is the Macaulay duration for bond $i$ in country $j$ in month $m$. The price deviations are weighted by the inverse of Macaulay's bond duration to guarantee that they are efficiently minimized in the yield space. In contrast to the direct minimization of the yield space, this method has the benefit that it avoids large computing costs that are necessary for the numerical conversion of prices into yields ( $\mathrm{Hu}$ et al., 2013). We use the method of generalized reduced gradients to minimize Eq. (2).

\section{B. Drivers of Illiquidity}

To study the drivers of illiquidity in the ASEAN-5 sovereign bond markets, we run a multiple time series regression for each country. We regress the first differences of the estimated noise on a comprehensive set of explanatory variables to identify the impact of potential drivers on monthly changes in noise:

$$
\Delta \text { Noise } e_{j m}=X^{\prime}{ }_{j m} \beta_{j}+\varepsilon_{j m}
$$

where $\Delta$ denotes the first difference operator, Noise ${ }_{j m}$ is the noise measure given in Eq. (1) for country $j$ in month $m$. The vectors $X_{j m}=\left(1, X_{j m, 1}, \ldots, X_{j m, k}\right)^{\prime}$ and $\beta_{j}=\left(\beta_{j, 0}, \beta_{j, 1}, \ldots, \beta_{j, k}\right)^{\prime}$ contain a set of $k+1$ explanatory variables and regression coefficients for each country $j$, respectively. The unexplained variation in the noise measure is denoted by $\varepsilon_{j m}$, where $\varepsilon_{j m} \mid X_{j m} \sim i . i . d .\left(0, \sigma_{\varepsilon_{j m}}^{2}\right)$.

\section{DATA}

In this section, we introduce the data used for curve fitting and estimating the noise measure. Moreover, we describe our explanatory variables used in the multiple regression and their theoretical relation to the noise measure.

\section{A. Sovereign Bonds}

We use monthly sovereign bond data for five ASEAN market countries, namely Indonesia, Malaysia, the Philippines, Singapore, and Thailand from Thomson Reuters Datastream. We set the time frame for our sample from January 2008 to January 2019 because, for most of the analyzed bond markets, there is not enough data available before 2008. For Malaysia, there is no bond-specific data available before August 2009, thus the Malaysian sample starts on this time point. In order to ensure a comparable sample, we use bonds which are non-callable, non-flower, and with no special tax treatment. We assume observations with negative prices or yields as well as yields larger than $30 \%$ as measurement errors and therefore exclude them from the sample. Since the number of bonds declared as measurement errors are negligible compared to the total number of bonds this should not affect our estimation. Bonds with remaining maturities less than one month are dropped from the sample, due to potential liquidity problems. We also remove bonds with maturity larger than 30 years as our sample only consists of 
a few such observations. Furthermore, we only consider bonds that are issued in the local currency.

On average, we have 35 bonds for Indonesia, 30 for Malaysia, 69 for the Philippines, 15 for Singapore, and 39 for Thailand with maturity between one month and 30 years. Contrary, Hu et al. (2013) use bonds and bills from one month to ten years for yield curve fitting and bonds from one year to ten years for estimating the noise measure. ${ }^{4}$ They argue that the short end of the yield curve is known to be noisier than other parts of the yield curve. Moreover, the short end is unlikely to be the object of arbitrage capital, which is the main motivation of the noise measure. Bonds with long maturity might suffer from instable supply, and thus could introduce unnecessary time-series noise to the measure.

\section{B. Explanatory Variables of Sovereign Bond Illiquidity}

This section contains a description of our explanatory variables and their theoretical relation to our estimated noise measure. The explanatory variables are grouped in common and country-specific variables.

\section{B1. Common Variables}

Corporate Bond Spread: The difference between the Moody's Aaa and Baa-rated corporate bond yields is commonly regarded as default spread. A decline in the credit supply leads to a decline in asset values, an increase in incentives to default, and a widening of yield spreads on private debt instruments of the economic downturn as lenders demand compensation for the expected increase in defaults (Gilchrist et al., 2009). Given this logic, the corporate bond spread can also be interpreted as a proxy for the aggregate credit cycle (Adrian et al., 2017). Although the empirical results are all related to the U.S. market, we assume the corporate bond spread as an indicator for global systemic risk, involving the ASEAN-5 market. Given the above results, we expect a positive relation between changes in the corporate bond spread, $\triangle C B S_{m^{\prime}}$ and noise changes.

Economic Policy Uncertainty: Several studies show that uncertainty reduces liquidity provision in financial markets (see e.g., Brunnermeier and Pedersen, 2009; Nagel, 2012). For example, increased uncertainty may induce additional risk premium requirements, which could force market makers to withdraw liquidity provision from the market. Baker et al. (2016) propose a monthly index of economic policy uncertainty (EPU) that reflects the frequency of articles in leading newspapers containing a trio of terms pertaining to the economy, uncertainty, and policy-related matters. Davis (2016) constructs a monthly index of global economic policy uncertainty (GEPU), which is a GDP-weighted average of national EPU indices for 21 countries that account for roughly $80 \%$ of global output at market

4 If we used the same data criteria as Hu et al. (2013), we would need to shrink the estimation period for most of the countries even further. As a result, we could not construct the noise measure during the global financial crisis, which would make our results less interpretable. Lastly, due to the low number of bond observations, observed maturities do not fully cover the estimation period of the estimated yield curves from one month to 30 years. The "gaps" within the estimation period might affect the reliability of curve fitting. 
exchange rates. We use the GEPU index to model economic policy uncertainty for the countries Indonesia, Malaysia, the Philippines, and Thailand. Given the above empirical and theoretical results, we expect a positive relation between changes in global economic policy uncertainty, $\triangle E P U_{m^{\prime}}$ and noise changes. For Singapore, we use changes in its economic policy uncertainty index, $\triangle E P U_{m}^{\text {Sing }}$, as Singapore is an international financial center and the most developed country within the ASEAN-5 group.

Implied Bond Volatility: To measure implied bond volatility, we use the CBOE 10-year U.S. Treasury Note Volatility Index (TYVIX), calculated and published by the Chicago Board Option Exchange (CBOE). ${ }^{5}$ The TYVIX measures a constant 30day expected volatility of 10-year Treasury Note futures prices and is calculated based on transparent pricing from Chicago Board of Trade's (CBOT) actively traded options on the Treasury Note futures. As there are no publicly available sovereign bond volatility indexes of the ASEAN-5 market, we use implied volatility in the U.S. Treasury market to proxy this indicator. Since existing literature provides empirical evidence of a negative relation between volatility and liquidity (see e.g., Engle et al., 2012; Adrian et al., 2017), we expect increases (decreases) in implied bond volatility, $\triangle B o n d V_{m}$ to be associated with an increase (decrease) in noise.

Term Structure Slope: We use differences between the 10-year and 2-year Singapore sovereign bond yield to calculate the riskless term structure slope. Since Singapore is the only country in the ASEAN-5 market, which has the highest possible rating on sovereign bonds (Aaa), we use its term structure slope for all countries. The existing literature finds that the slope of the yield curve has significant predictive power in explaining business cycle fluctuations (see e.g., Estrella and Hardouvelis, 1991; Rudebusch and Williams, 2009). An increase in the slope of the term structure is a common indicator of prospective economic growth (see e.g., Fama and French, 1989; Martell, 2008; Iyke, 2017). Following this logic, a steeper slope may indicate a growing economy leading to higher liquidity in the market. Consequently, we would expect a positive relation between $\Delta$ Slope $_{m}$ and noise changes.

VIX: The CBOE Volatility Index (VIX) is a popular measure of the stock market's expectation of volatility, which is also known as "fear index" or "fear gauge" (see e.g., Whaley, 2000; Simon and Wiggins, 2001; Whaley, 2009). Moreover, there is some evidence that VIX is a cross-market fear gauge. An increase in VIX suppresses returns of the sock markets in Indonesia, Malaysia, the Philippines, Singapore, and Thailand during the U.S. subprime crisis (Abduhl-Rahman and Sidek, 2011; Lim, 2009). In addition, Bao et al. (2011) show that monthly changes in aggregate bond market liquidity are strongly related to changes in VIX. Since market illiquidity increases when VIX increases, a positive (negative) change in VIX, i.e. $\Delta V I X_{m^{\prime}}$ should be associated with increasing (decreasing) noise.

Adrian et al. (2017) use the Merrill Lynch Option Volatility Estimate index (MOVE) to calculate implied Treasury volatility. MOVE data is not are not available publicly, therefore we use the TYVIX. As both indexes measure implied volatility in the Treasury market and the CBOE is a well-known provider of volatility indexes (e.g. VIX), we also assume the TYVIX as a reliable measure. 


\section{B2. Country-specific Variables}

Local Equity Market Return: The return of the local equity index is an indicator of the country-specific business climate. During times of market turmoil, stock prices are informative linkages between the real and financial sides of economy, due to their forward-looking nature. Chung and Chuwonganant (2018) show that during crisis periods lower stock returns do not just arise from greater expected risk premiums but also from greater expected illiquidity premiums. Moreover, the authors provide evidence that stock's return is more sensitive to unexpected changes in volatility when liquidity disappears. Following this logic, we expect a negative relationship between changes in local equity market returns, $R E_{i m^{\prime}}$ and changes in noise. The local monthly compounding equity market returns are calculated by using monthly closing prices from the following equity market indexes: IDX Composite (Indonesia), KLCI 30 (Malaysia), PSE 30 (the Philippines), STI 30 (Singapore), and SET 100 (Thailand). ${ }^{6}$

Local Gold Return: Gold is a prominent safe haven, while also being a risky asset. However, the function of gold as safe haven in the ASEAN market literature is scarce. According to Ziaei (2012), gold can act as a hedge against equity, but their results show that the gold price cannot be considered as a safe haven in the ASEAN +3 market. ${ }^{7}$ Contrary, the results of a more recent study from Nguyen et al. (2016), using a mixed-copula approach, show that gold may be a safe haven asset during a market crash for Malaysia, Singapore, and Thailand, but not for Indonesia and the Philippines. Despite opposing results from existing literature, we use the local gold return, $R G_{j m^{\prime}}$ as an explanatory variable and expect a positive relationship between the local gold return and changes in noise, as an increase in noise indicates the need for a safe haven. The gold returns are calculated for each country using the London gold bullion market's monthly gold fixing prices previously converted into local currency.

GDP Growth Rate: Following the intuition of Hu et al. (2013), which we use to calculate our liquidity measure, a downturn in the overall economy could lead to a deterioration in arbitrage capital, and, thus, increase illiquidity. Contrary, during a normal business cycle there should be plenty of arbitrage available leading to a low level of illiquidity. As a result, we control for GDP growth as growth in the aggregate output of an economy. Since GDP statistics are available only at a quarterly frequency, we use linear interpolation (see e.g., Adrian et al., 2017) to obtain the monthly GDP level for each country. Based on the GDP level, we calculate the monthly GDP growth rate. We expect a negative relation between relative change in the GDP growth rate, $\triangle G D P_{j m^{\prime}}$ and the noise measure.

Inflation Rate: We also consider the inflation rate, measured by the monthly relative changes in the local consumer price index (CPI). Referring to the logic of the Phillips curve, inflation controls for the output gap and future price level expectations of an economy. We expect that the relative change in the inflation rate, $\Delta$ Inflation $_{j m^{\prime}}$ is negatively related to changes in the noise measure.

6 The abbreviations have the following meaning: Indonesia Stock Exchange Composite (IDX Composite), Kuala Lumpur Composite Index 30 (KLCI 30), Philippine Stock Exchange Composite Index 30 (PSE 30), FTSE Straits Times Index 30 (STI 30) and Stock Exchange of Thailand Index (SET 100).

7 In Ziaei's (2012) study, the ASEAN +3 market includes five ASEAN countries (Indonesia, Malaysia, Philippines, Singapore, and Thailand) as well as China, Japan and South Korea. 
Table 1 summarizes the explanatory variables and provides the data sources as well as expected effect on changes in the noise measure.

Table 1.

Definition of Explanatory Variables

This table contains a summary of the explanatory variables including their expected sign and the data source.

\begin{tabular}{|c|c|c|c|}
\hline \multirow[t]{2}{*}{ Variable } & Description & Source & $\begin{array}{l}\text { Expected } \\
\text { Sign }\end{array}$ \\
\hline & \multicolumn{3}{|c|}{ Panel A: Common variables } \\
\hline$\triangle C B S_{m}$ & $\begin{array}{l}\text { Changes in the corporate bond spread } \\
\text { (Moody's Baa-Aaa corporate bond yields) }\end{array}$ & FRED & + \\
\hline$\triangle E P U_{m}$ & $\begin{array}{c}\text { Changes in the Global Economic Policy } \\
\text { Uncertainty Index (GEPU) }\end{array}$ & $\begin{array}{l}\text { http://www.policyuncertainty. } \\
\text { com }\end{array}$ & + \\
\hline$\Delta B o n d V_{m}$ & $\begin{array}{l}\text { Changes in the CBOE 10-year U.S. } \\
\text { Treasury Note Volatility Index (TYVIX) }\end{array}$ & CBOE & + \\
\hline$\Delta$ Slope $_{m}$ & $\begin{array}{l}\text { Slope of the Singapore sovereign bond } \\
\text { yield curve }\end{array}$ & $\begin{array}{l}\text { Monetary Authority of Singapore } \\
\text { (MAS) }\end{array}$ & + \\
\hline \multirow[t]{2}{*}{$\Delta V I X_{m}$} & $\begin{array}{l}\text { Changes in the CBOE Volatility Index } \\
\text { (VIX) }\end{array}$ & CBOE & + \\
\hline & \multicolumn{3}{|c|}{ Panel B: Country-specific variables } \\
\hline$\Delta E P U_{m}^{\text {Sing }}$ & $\begin{array}{l}\text { Changes in Singapore's Economic Policy } \\
\text { Uncertainty Index }\end{array}$ & $\begin{array}{l}\text { http://www.policyuncertainty. } \\
\text { com }\end{array}$ & + \\
\hline$R E_{j m}$ & $\begin{array}{l}\text { Local equity market Return: } \\
\text { IDX Composite (Indonesia), KLCI } 30 \\
\text { (Malaysia), PSE } 30 \text { (Philippines), STI } 30 \\
\text { (Singapore) and SET } 100 \text { (Thailand) }\end{array}$ & Thomson Reuters Eikon & - \\
\hline$R G_{i m}$ & Gold return in local currency & FRED, Yahoo Finance & + \\
\hline$\Delta G D P_{j m}$ & Relative changes in GDP levels & Thomson Reuters Eikon & - \\
\hline Inflation $_{j m}$ & $\begin{array}{l}\text { Relative changes in the consumer price } \\
\text { index (CPI) }\end{array}$ & $\begin{array}{l}\text { Bank of International Settlement } \\
\text { (BIS) }\end{array}$ & - \\
\hline
\end{tabular}

\section{EMPIRICAL ANALYSIS}

In this section, we first present and discuss the results of the sovereign bond illiquidity measure Noise $_{j m}$ for each ASEAN country, including the yield curve fitting process as a main part of illiquidity estimation. Then, we examine the ability of several common variables $\left(\triangle C B S_{m^{\prime}}, \Delta E P U_{m^{\prime}} \Delta B o n d V_{m^{\prime}}, \Delta S\right.$ Slope $_{m^{\prime}}$ and $\left.\triangle V I X_{m}\right)$ as well as country-specific variables $\left(\Delta E P U_{m}^{\text {sing }}, R E_{j m^{\prime}} R G_{j m^{\prime}}, \Delta G D P_{j m^{\prime}}\right.$ and $\Delta$ Inflation $\left._{j m}\right)$ to explain changes in the noise measure.

\section{A. Curve Fitting Results}

In this section, we present some exemplary results of fitted yield curves using the Svensson (1994) approach. For this purpose, we plot several examples of modelimplied yield curves as lines and the market observed bond yields, marked by " + ", " $\mathrm{o}$ " or " $\mathrm{x}$ " for each ASEAN-5 country in Figure 1. For each country, three different months are shown: One month during the global financial crisis represented by November 2008 " + " and two random months, September 2014 "o" and April 2017 
" $x$ ", which represent tranquil months in terms of yield curve fitting. We expect the observed yields during tranquil periods to be roughly "in line" across the entire yield curve, so that the curve fitting process works well. Contrarily, in November 2008, we expect high levels of dispersion in bond yields over the entire yield curve, leading to a higher noise and a higher level of illiquidity. Observed bond yields with a higher maturity are approximately in line. As the higher maturity bond yields do not seem to capture a lot of information for our illiquidity measure, we focus on the first 15 years in the following analysis of the plots of the respective ASEAN-5 countries. For Indonesia and the Philippines, there is a lack of observed yields within the mid-term yield curve in November 2008.

Figure 1.

\section{Estimated model-implied Yield and market-observed Yield Curves}

The figure plots estimated model-implied yield curves, shown as solid lines, and the market-observed bond yields, marked by " + ", " $\mathrm{o}$ " or " $\mathrm{x}$ " for countries Indonesia, Malaysia, the Philippines, Singapore, and Thailand are estimated at September 2014 and April 2017 in order to show the yield curve fitting in tranquil periods.
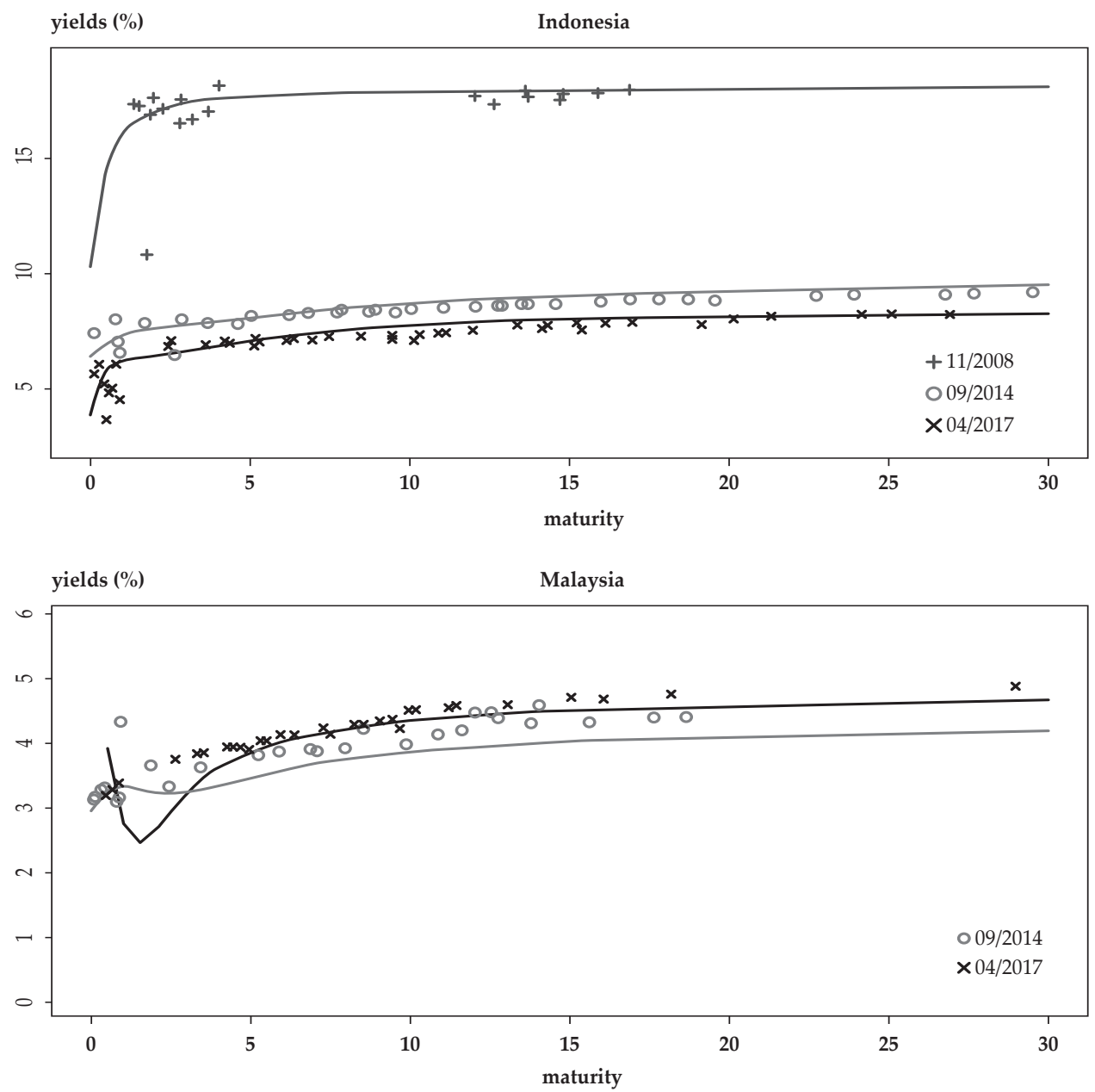
Figure 1.

Estimated model-implied Yield and market-observed Yield Curves (Continued)
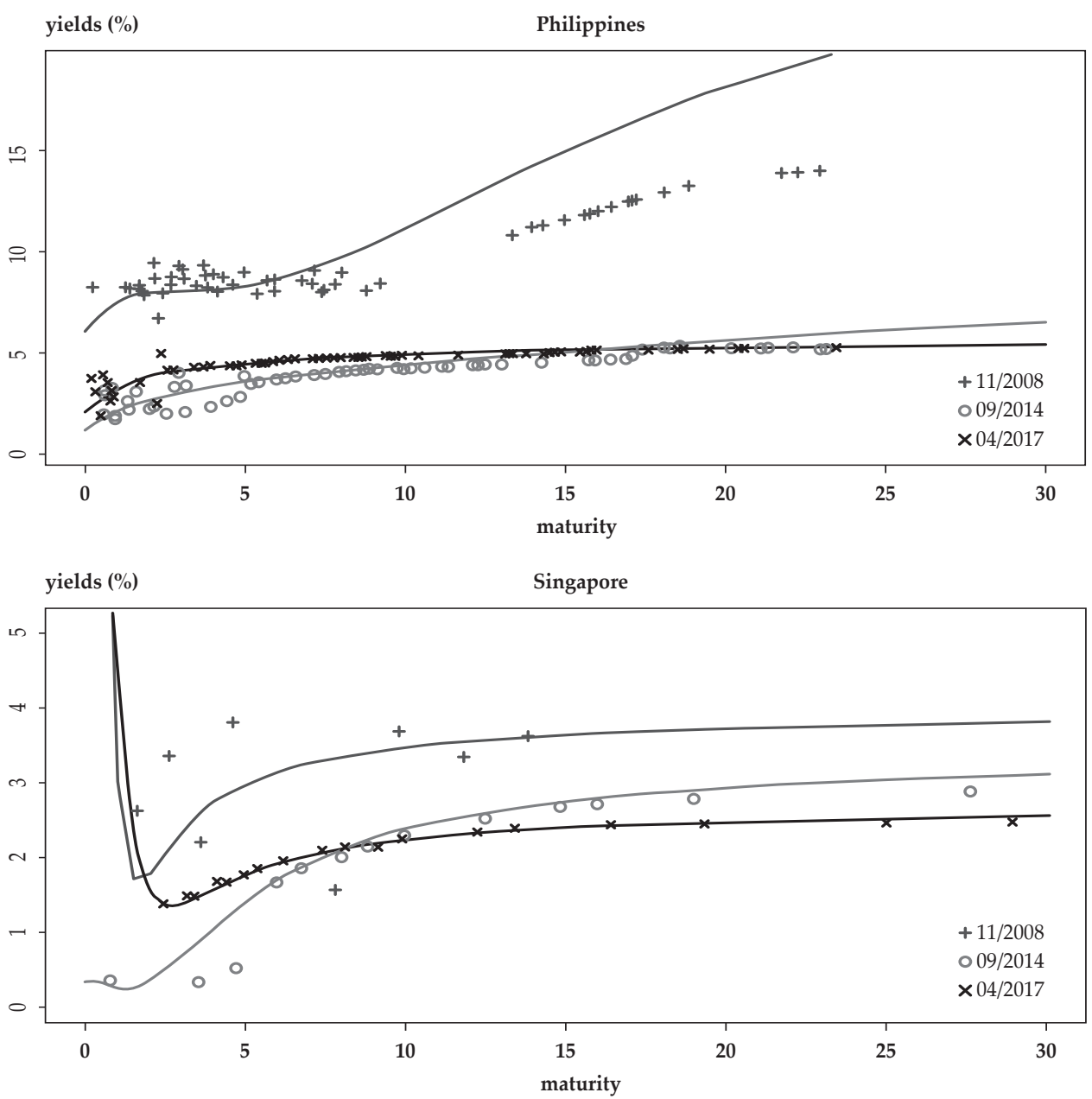

yields (\%)

Thailand

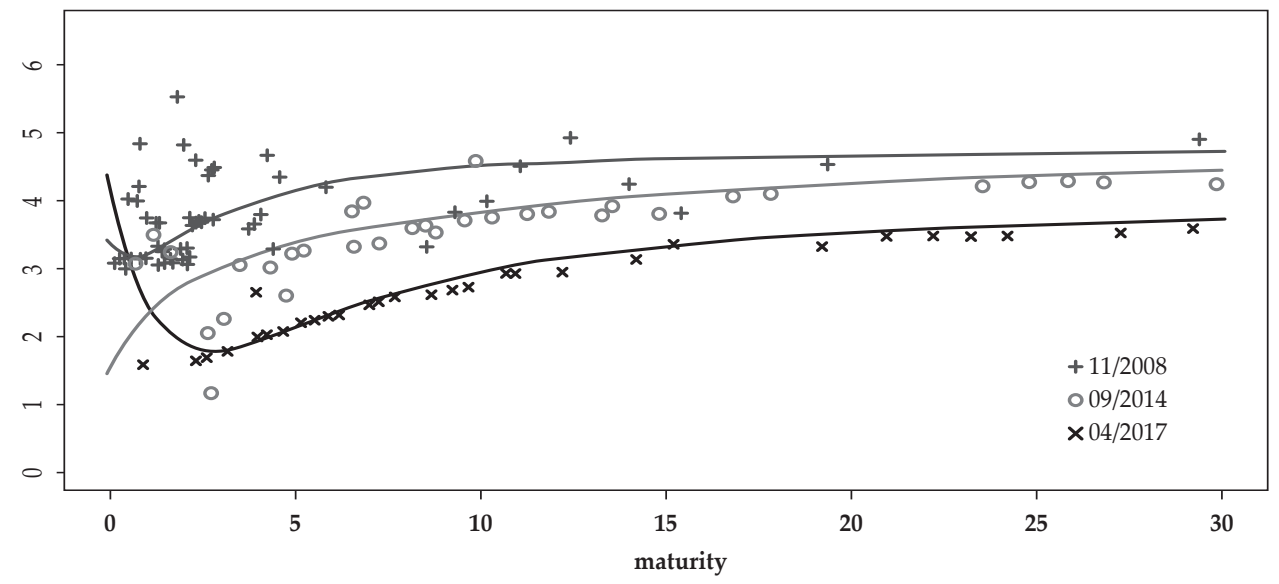


These "gaps" might be a problem, since information for the missing interval of maturities are not considered in our illiquidity measure. Moreover, the yield curve of the Philippines "slips away" from the observed yields after the gap. Thus, an increase in noise does not arise from dispersion in long-term maturity bond yields, but from bad curve fitting. We assume this could be due to either the gaps within the yield curve and/or a lack of computing capacity. Despite this problem, the graph also shows a way higher dispersion in bond yields up to ten years maturity for November 2008 compared to the other months. Thus, the results of noise still follow the right intuition, however, the level might be a little overstated. Contrarily, the yield curve fitting process for the tranquil months works well for Indonesia and the Philippines.

For Singapore, the yield curves in November 2008 and April 2017 move freely at the very short end, showing a big downswing, proceeding from a high level that does not fit the rest of the yield curve. The free movement at the very short end arises from a lack of data for yields with low maturities. Despite the fact that we have no information from the short end of the yield curve for our illiquidity measure, the lack of short maturity bond yields does not affect our measure, as we do not calculate deviations when no yields are observed. More importantly, the rest of the yield curves and the observed yields for Singapore show that the increases in noise, during the financial crisis, were not a result of poor curve fitting on this month. Instead, they were caused by high levels of dispersion in bond yields across the yield curve, while the observed yields during tranquil months were more in line. This important fact can also be discovered for Thailand. For Malaysia the yield curve fitting works quite well, despite showing more noise in September 2014.

\section{B. Illiquidity (Noise) Measure}

Next, we analyse the estimated illiquidity measures for the various markets. Figure 2 illustrates the monthly evolution of sovereign bond illiquidity, Noise ${ }_{i m^{\prime}}$ while Table 2 presents key descriptive statistics of monthly sovereign bond illiquidity and changes in sovereign bond illiquidity, $\Delta N_{\text {oise }}{ }_{i m}$. The plot of illiquidity levels, shown in Figure 2, provides very heterogeneous results. The empirical result of Singapore's sovereign bond market noise follows our a priori expectations, jumping up to its maximum of roughly 87 basis points during the global financial crisis, while fluctuating around a low level of roughly 5 basis points after the crisis, showing the lowest level of noise during tranquil periods of all the ASEAN- 5 bond markets. 


\section{Figure 2.}

Monthly Evolution of Sovereign Bond Illiquidity in ASEAN Countries

The plots contain Noise $e_{i m}$ in basis points for Indonesia, Malaysia, the Philippines, Singapore, and Thailand. The sample period is from January 2008 to January 2019, except for Malaysia which starts on August 2009.
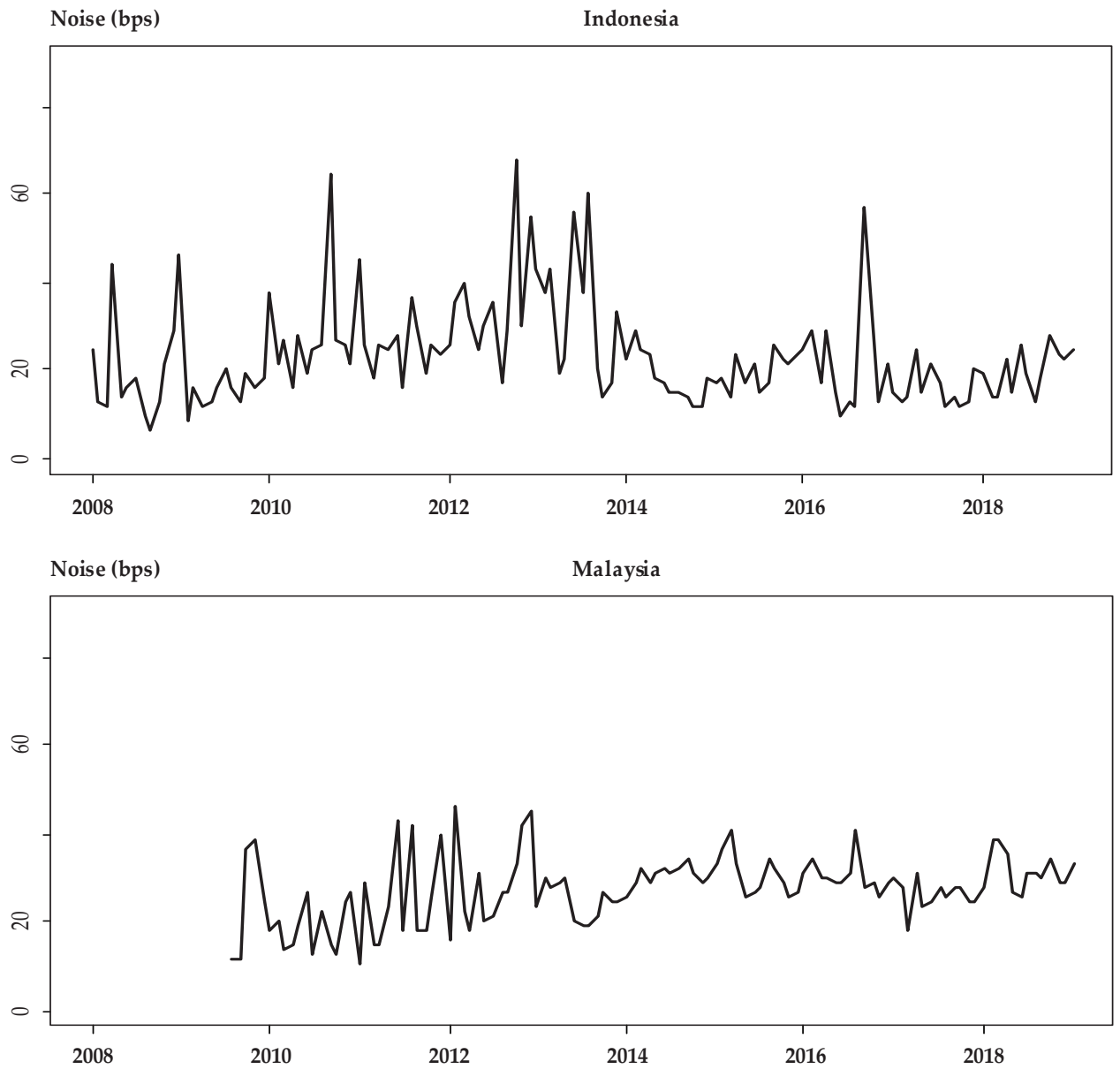

Noise (bps)

Philippines

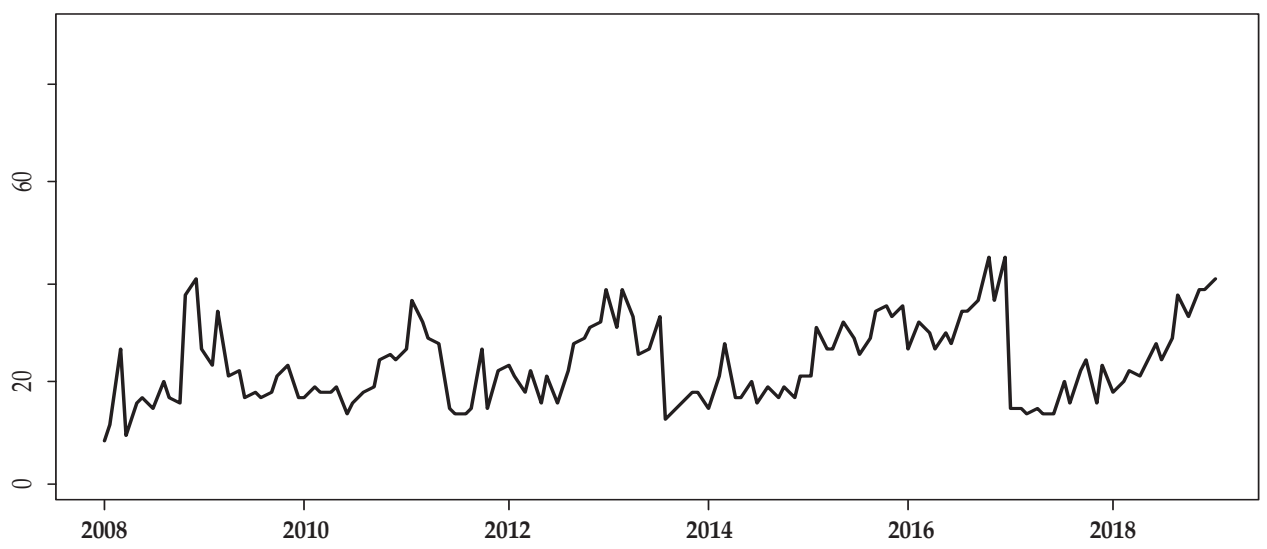


Figure 2.

Monthly Evolution of Sovereign Bond Illiquidity in ASEAN Countries (Continued)
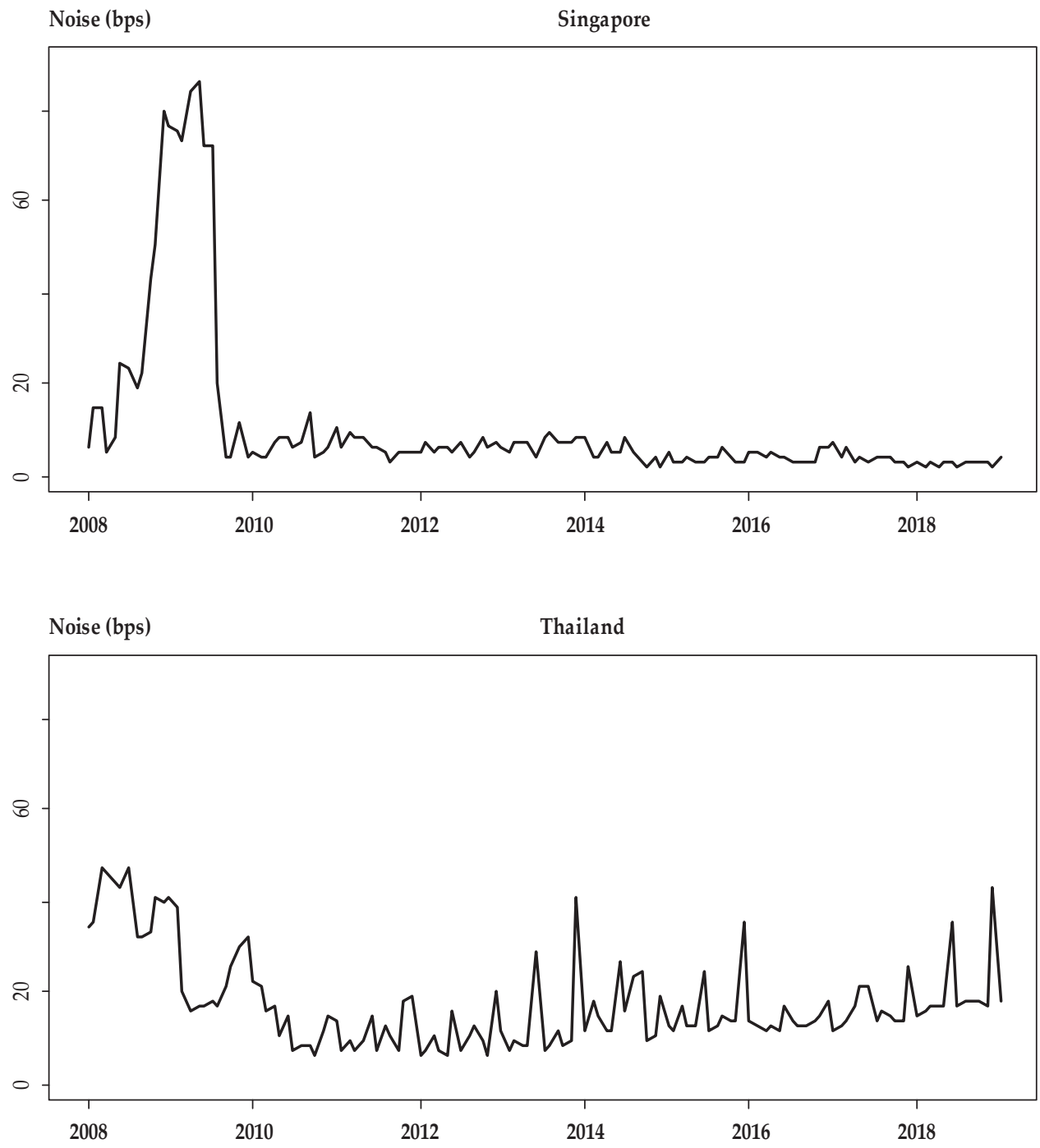





Contrarily, the time variation of noise levels for all other ASEAN-5 countries are difficult to interpret. The results of the Philippines and Thailand show a higher level of noise of around 40 basis points during the financial crisis. However, after the financial crisis there are plenty of jumps in noise, which cannot be linked to a market-wide liquidity event, contrary to our a priori expectations. Furthermore, Thailand shows a lower average level of noise (17.6 basis points) compared to the Philippines (23.8 basis points), whereas the standard deviation of Thailand is higher.

The noise level results of Indonesia show the highest level of discontinuity, spiking up and plummeting frequently within a range from around 5 to 68 basis points, while showing a mean of 23.1 basis points. For Malaysia, the noise level results also indicate high fluctuation around the highest mean of all countries (27.3 basis points). As there are no bond observations before August 2009, we cannot compare these tranquil period results to the global financial crisis. Moreover, the descriptive statistics of Malaysia can hardly be compared to the other countries as they are based on a different sample period. For all countries, except for Malaysia, the Jarque-Bera statistics imply that the empirical distribution of noise levels deviates strongly from the normal distribution.

Besides the fact that the noise level results for Indonesia, Malaysia, the Philippines, and Thailand deviate quite far from our expectations, our empirical results for these markets show jumps in noise during the financial crisis. These results indicate a potential, economically plausible explanation for the unexpected time series variation in noise. While Singapore has the highest possible credit rating (i.e. Aaa) on sovereign bonds throughout the whole sample period, and can, thus, be treated as a safe haven, the remaining countries have a weaker rating. In addition, arbitrageurs also account for basic market liquidity, which can be determined by market size and tightness (bid/ask spread). Therefore, the safe haven rating and a higher level of basic liquidity in Singapore's sovereign bond market could also explain why in tranquil periods small deviations in this yield curve are eliminated by arbitrage immediately, while there are a delayed reaction and higher yield curve deviations in the other markets (Singapore's average noise level is 10.77, which is also the lowest among all ASEAN-5 countries, see Table 2).

In addition, Table 2 presents some further descriptive statistics about the monthly changes in noise, $\Delta$ Noise $_{j m}$. Since we calculate our measure in basis points, the mean of the noise changes is very close to zero for all countries. Moreover, for all countries, the Jarque-Bera statistic reveals that the empirical distribution deviates strongly from the normal distribution. The kurtosis of Singapore and the Philippines is higher than three, which indicates a leptokurtic distribution. Malaysia, the Philippines, and Singapore are characterized by a negative skewness, while Singapore shows the highest absolute level of skewness (-2.811). Since the Augmented Dickey-Fuller (ADF) and the Phillips-Perron (PP) unit root tests indicate that the noise levels for Singapore are not stationary, we use the changes in noise instead of levels for further empirical analysis. The reported unit root test statistics clearly confirm the absence of a unit root in noise changes. In addition, we find that noise changes are quite weakly correlated between the countries, whereas the correlation matrix of the noise levels shows mild correlations between the pairs Singapore/Malaysia and Singapore/Thailand. 


\section{Drivers of Illiquidity}

In this section, we study the explanatory power of potential illiquidity drivers. For this purpose, we estimate Eq. (3) for each ASEAN-5 sovereign bond market. In addition, we impose $\mathrm{AR}(1)$ and $\mathrm{AR}(2)$ terms in the regression to account for potential serial correlation. Moreover, we consider two different sample periods. The first sample period, which is used in Table 3, spans from January 2008 to January 2019 and includes the global financial crisis as a market-wide liquidity event. Since the Malaysian bond data is not available throughout the whole sample period, we exclude the country from the first estimation in order to obtain comparable results. The second sample period, which is used in Table 4, is from August 2009 to January 2019 and includes all ASEAN countries, while not considering a marketwide liquidity event. Since not all potential illiquidity drivers have the same units, we standardize any time series by using its sample mean and standard deviation. In order to achieve a reliable inference on statistical significance of the results, we estimate heteroskedasticity and serial correlation adjusted standard errors of Newey and West (1987) throughout all the regression specifications. We use the variance inflation factor (VIF) to examine whether the outcomes, given in Tables 3 and 4, are distorted by multicollinearity. Unreported results reveal that for all explanatory variables, $V I F_{j}<5$ holds, therefore, there is no severe multicollinearity in our model.

Given Table 3, we find that our regression model for Singapore has the highest explanatory power, exhibiting an adjusted $R^{2}$ of nearly $28 \%$. In addition, for this model, all estimated signs of significant variables and at the same time most of the estimated signs of all explanatory variables are in line with the expected signs. This is not the case for the rest of the countries, which is not surprising as illiquidity in these countries is more noise driven.

Table 3.

Illiquidity Drivers Including the Global Financial Crisis

The table shows estimated $\beta$-coefficients and $t$-statistics (in parentheses) of Eq. (3) for the monthly changes in noise measure for Indonesia, the Philippines, Singapore, and Thailand. For Singapore, we estimate two regressions: Singapore (1) comprises the same variables as all other countries, while Singapore (2) replaces the common variable

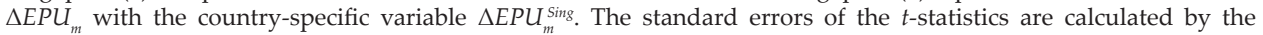
heteroskedasticity and autocorrelation consistent covariance estimator of Newey and West (1987). The regression coefficients are standardized. Significance at the 1,5 , and 10 percent level is denoted by ${ }^{* * *}, * *$, and $*$, respectively. The sample period is from January 2008 to January 2019.

\begin{tabular}{lccccc}
\hline Variable & Indonesia & Philippines & Singapore (1) & Singapore (2) & Thailand \\
\hline \multicolumn{5}{c}{ Panel A: Common Variables } \\
\hline$\triangle C B S_{m}$ & -0.0584 & $1.0886^{* *}$ & $3.1662^{* * *}$ & $3.2007^{* * *}$ & 0.0848 \\
& $(-0.08)$ & $(2.29)$ & $(6.18)$ & $(6.29)$ & $(0.17)$ \\
$\Delta E P U_{m}$ & -0.7417 & $-1.3487^{* * *}$ & $0.7948^{* *}$ & - & 0.6051 \\
& $(-0.87)$ & $(-3.07)$ & $(2.50)$ & - & $(1.10)$ \\
$\Delta$ Bond $_{m}$ & 1.0080 & $1.0003^{*}$ & 0.6558 & 0.6308 & 0.1626 \\
& $(0.93)$ & $(1.80)$ & $(1.21)$ & $(1.12)$ & $(0.36)$ \\
$\Delta$ Slope $_{m}$ & 0.4325 & -0.4010 & 0.4866 & 0.5101 & $1.7449^{* *}$ \\
& $(0.26)$ & $(-0.95)$ & $(1.35)$ & $(1.43)$ & $(2.11)$ \\
$\Delta$ VIX $_{m}$ & 0.2081 & $-1.1106^{* *}$ & -0.4409 & -0.4335 & 0.2977 \\
& $(0.24)$ & $(-2.50)$ & $(-0.82)$ & $(-0.83)$ & $(0.39)$ \\
\hline
\end{tabular}


Table 3.

Illiquidity Drivers Including the Global Financial Crisis (Continued)

\begin{tabular}{|c|c|c|c|c|c|}
\hline Variable & Indonesia & Philippines & Singapore (1) & Singapore (2) & Thailand \\
\hline \multicolumn{6}{|c|}{ Panel B: Country-specific Variables } \\
\hline \multirow{2}{*}{$\Delta E P U_{m}^{\text {Sing }}$} & - & - & - & $0.9138^{* * *}$ & - \\
\hline & - & - & - & $(3.03)$ & - \\
\hline \multirow[t]{2}{*}{$R E_{j m}$} & 0.5543 & -12.1613 & 0.0366 & 0.0781 & -0.5566 \\
\hline & $(0.56)$ & $(-1.22)$ & $(0.05)$ & $(0.10)$ & $(-0.87)$ \\
\hline \multirow{2}{*}{$R G_{j m}$} & 0.6461 & $-15.1860^{*}$ & -0.1744 & -0.1772 & 0.1763 \\
\hline & $(0.68)$ & $(-1.69)$ & $(-0.46)$ & $(-0.46)$ & $(0.23)$ \\
\hline \multirow{2}{*}{$\Delta G D P_{j m}$} & -0.4506 & -3.6694 & $-1.4074^{* * *}$ & $-1.4462^{* * *}$ & -0.3829 \\
\hline & $(-0.48)$ & $(-0.39)$ & $(-3.05)$ & $(-3.15)$ & $(-0.94)$ \\
\hline \multirow[t]{2}{*}{$\Delta_{\text {Inflation }}{ }_{j m}$} & 1.0219 & 29.1179 & -0.3869 & -0.3847 & -0.5904 \\
\hline & $(0.97)$ & $(0.33)$ & $(-1.06)$ & $(-1.09)$ & $(-1.28)$ \\
\hline \multirow[t]{2}{*}{$\Delta$ Noise $_{j m-1}$} & $-8.2982^{* * *}$ & $-2.4804^{* * *}$ & 0.3219 & 0.3291 & $-4.8373^{* * *}$ \\
\hline & $(-9.58)$ & $(-4.21)$ & $(1.01)$ & $(1.00)$ & $(-5.21)$ \\
\hline \multirow{2}{*}{$\Delta$ Noise $_{j m-2}$} & $-3.9567^{* * *}$ & $-0.9891^{*}$ & 0.4971 & 0.4798 & $-2.6267^{* * *}$ \\
\hline & $(-3.47)$ & $(-1.88)$ & $(0.88)$ & $(0.84)$ & $(-3.29)$ \\
\hline$R^{2}$ & 0.2954 & 0.3167 & 0.3391 & 0.3430 & 0.3224 \\
\hline Adjusted $R^{2}$ & 0.2297 & 0.2530 & 0.2775 & 0.2818 & 0.2592 \\
\hline Observations & 130 & 130 & 130 & 130 & 130 \\
\hline
\end{tabular}

We start with the results of the common variables. The changes in corporate bond spreads are highly significant for Singapore and significant (at the 5 percent level) for the Philippines with the expected positive sign. This result seems highly sensible, since one of the fundamental causes of the global financial crisis was a credit boom (Acharya and Richardson, 2009). Global economic policy uncertainty is significant for the Philippines and Singapore, showing the expected positive sign for Singapore and an unexpected negative sign for the Philippines. The result for Singapore complies with the theory that uncertainty reduces liquidity provision in financial markets. Concerning the relation between changes in implied bond volatility and changes in noise, we find a significant and expectedly positive relation for the Philippines, which is significant at the 10 percent level. For changes in the term structure slope, we find a significant positive result for Thailand. Finally, changes in VIX are significantly negatively related to changes in noise for the Philippines, opposing our expectations.

We continue by examining the estimation results of the country-specific variables. The Singapore-specific changes in economic policy uncertainty, which are only used in model "Singapore (2)", show a higher expectedly positive significance than changes in global economic policy uncertainty. This indicates that the noise measure also captures some information about the country-specific liquidity conditions. Local equity returns are not significant in any of the ASEAN-5 sovereign bond markets, while the GDP growth rate is highly significant, showing an expectedly negative sign in Singapore. Thus, the business cycle might be more related to our illiquidity measure than the more forward-looking local business climate. Concerning the relation between the local gold return and changes 
in noise, we only find a single negative relation for the Philippines, which is significant at the 10 percent level. The negative coefficient is not in line with the theoretical expectation. In times of a market-wide liquidity stress event, investors might be forced to sell some or all of their holdings, which can lead to a decline in returns. The inflation rate, as our second macroeconomic variable, is not significant in any of the countries. Given its forward-looking character, following the assumptions of the Phillips Curve, the results are consistent with the findings for the local business climate (expressed by local equity returns). Thus, the aggregate business cycle might be a more important macroeconomic explanatory variable than the inflation rate. For Indonesia, the Philippines, and Thailand, we report negative autocorrelation, which is highly significant. This underlines our considerations in the previous section econometrically that the results in noise for these countries are not persistent as expected, but mean reverse. Overall, we find consistent econometric results for Singapore. The main driver of illiquidity in Singapore's sovereign bond market is the corporate bond spread, as a proxy for the aggregate credit cycle. Moreover, an increase in economic policy uncertainty and declines in the aggregate business cycle significantly drive sovereign bond illiquidity in Singapore. For Indonesia, the only explanatory variables that drive illiquidity are negative autocorrelation of first and second order, reflecting the mean reverse results of noise. The Philippines and Thailand are also driven by negative autocorrelation. However, in these sovereign bond markets, we can also identify some significant explainable variables, where the signs of the coefficients follow our theoretical expectations.

Table 4 includes the information on the Malaysian sovereign bond market, while excluding the global financial crisis event. By not considering any marketwide liquidity event within this sample period, our results show that changes in noise are mainly driven by negative autocorrelation in Indonesia, Malaysia, Singapore, and Thailand, implying a mean reversion in noise changes. In the Philippines, first order autocorrelation is negative at the 5 percent level. Indonesia and Malaysia do not show any other illiquidity driver, while, for the Philippines, changes in global economic policy uncertainty are significant at the 5 percent level and negatively related to changes in noise, opposing our theoretical expectations. The contradicting sign of global economic policy uncertainty for the Philippines may be explained by a paradigm shift in foreign direct investments due to a shrinking share of U.S. direct investment in the total share of the Philippines foreign direct investments in the recent years as well as increased risk aversion in the region. The changes in corporate bond spread for Singapore turn from a highly significant positive result in Table 3 to a significant negative result in Table 4. During the global financial crisis, illiquidity in Singapore's sovereign bond market increased sharply and declined quickly afterwards to its normal level (see Figure 2). This might explain the sign change as both corporate bond yield spreads as well as the illiquidity of Singapore sovereign bond market are at a high level during the global financial crisis. However, in tranquil periods, Singapore's sovereign bond market is very liquid and therefore its illiquidity is negatively related to the corporate bond market. Lastly, changes in term structure slope are highly significant in Thailand and significant at the 5 percent level in Singapore, showing opposite signs. Overall, we find very few significant variables and most 
of them are contrary to the theoretical expectations. The Singapore sovereign bond market, especially, shows completely opposing results compared to the first sample period, which included the global financial crisis. However, these are not bad results at all, as they indicate that our explanatory variables can explain illiquidity jumps during a market-wide illiquidity event but not the fluctuation of noise on a very low level during tranquil periods.

Table 4.

Illiquidity Drivers Excluding a Market-Wide Liquidity Event

The table shows estimated $\beta$-coefficients and $t$-statistics (in parentheses) of Eq. (3) for the monthly changes in the noise measure for Indonesia, the Philippines, Singapore, and Thailand. For Singapore, we estimate two regressions: Singapore (1) comprises the same variables as all other countries, while Singapore (2) replaces the common variable

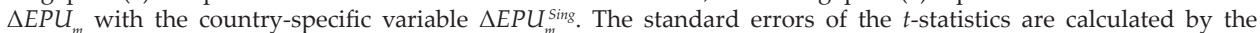
heteroskedasticity and autocorrelation consistent covariance estimator of Newey and West (1987). The regression coefficients are standardized. Significance at the 1,5 , and 10 percent level is denoted by ${ }^{* * * * * *}$, and *, respectively. The sample period is from August 2009 to January 2019.

\begin{tabular}{|c|c|c|c|c|c|c|}
\hline Variable & Indonesia & Malaysia & Philippines & $\begin{array}{l}\text { Singapore } \\
\text { (1) }\end{array}$ & $\begin{array}{l}\text { Singapore } \\
\text { (2) }\end{array}$ & Thailand \\
\hline \multicolumn{7}{|c|}{ Panel A: Common Variables } \\
\hline$\triangle C B S_{m}$ & $\begin{array}{l}-0.1238 \\
(-0.09)\end{array}$ & $\begin{array}{l}-0.7757 \\
(-0.91)\end{array}$ & $\begin{array}{c}0.4774 \\
(0.79)\end{array}$ & $\begin{array}{c}-0.396^{* *} \\
(-2.16)\end{array}$ & $\begin{array}{l}-0.386^{* *} \\
(-2.12)\end{array}$ & $\begin{array}{l}0.6619 \\
(1.30)\end{array}$ \\
\hline$\triangle E P U_{m}$ & $\begin{array}{c}0.0611 \\
(0.07)\end{array}$ & $\begin{array}{c}-0.3622 \\
(-0.46)\end{array}$ & $\begin{array}{c}-1.1566^{* *} \\
(-2.12)\end{array}$ & $\begin{array}{c}0.1973 \\
(1.17)\end{array}$ & $\begin{array}{l}- \\
-\end{array}$ & $\begin{array}{l}0.9997 \\
(1.57)\end{array}$ \\
\hline$\Delta B o n d V_{m}$ & $\begin{array}{c}0.1078 \\
(0.09)\end{array}$ & $\begin{array}{l}-0.2674 \\
(-0.46)\end{array}$ & $\begin{array}{l}0.5111 \\
(0.68)\end{array}$ & $\begin{array}{c}0.0487 \\
(0.23)\end{array}$ & $\begin{array}{c}0.0390 \\
(0.18)\end{array}$ & $\begin{array}{l}-0.1585 \\
(-0.24)\end{array}$ \\
\hline$\Delta$ Slope $_{m}$ & $\begin{array}{c}1.2456 \\
(0.68)\end{array}$ & $\begin{array}{l}-1.0929 \\
(-1.66)\end{array}$ & $\begin{array}{c}-0.1209 \\
(-0.28)\end{array}$ & $\begin{array}{c}-0.4026^{* *} \\
(-2.45)\end{array}$ & $\begin{array}{c}-0.3871^{* *} \\
(-2.43)\end{array}$ & $\begin{array}{c}2.1828^{* * *} \\
(2.78)\end{array}$ \\
\hline$\Delta V I X_{m}$ & $\begin{array}{l}0.8346 \\
(0.84)\end{array}$ & $\begin{array}{c}0.6735 \\
(0.88)\end{array}$ & $\begin{array}{c}-0.9039^{*} \\
(-1.91)\end{array}$ & $\begin{array}{c}0.2263 \\
(1.11) \\
\end{array}$ & $\begin{array}{c}0.2224 \\
(1.09)\end{array}$ & $\begin{array}{c}0.5277 \\
(0.81)\end{array}$ \\
\hline \multicolumn{7}{|c|}{ Panel B: Country-specific Variables } \\
\hline$\Delta E P U_{m}^{\text {Sing }}$ & $\begin{array}{l}- \\
-\end{array}$ & $\begin{array}{l}- \\
-\end{array}$ & $\begin{array}{l} \\
-\end{array}$ & $\begin{array}{l} \\
-\end{array}$ & $\begin{array}{l}0.2547 \\
(1.52)\end{array}$ & - \\
\hline$R E_{j m}$ & $\begin{array}{c}0.8599 \\
(0.73)\end{array}$ & $\begin{array}{c}-0.1266 \\
(-0.13)\end{array}$ & $\begin{array}{c}-16.7762 \\
(-1.38)\end{array}$ & $\begin{array}{c}-0.2606 \\
(-1.48)\end{array}$ & $\begin{array}{l}-0.2446 \\
(-1.41)\end{array}$ & $\begin{array}{l}-0.4125 \\
(-0.63)\end{array}$ \\
\hline$R G_{j m}$ & $\begin{array}{c}1.0943 \\
(1.08)\end{array}$ & $\begin{array}{c}0.5576 \\
(0.67)\end{array}$ & $\begin{array}{c}-10.9196 \\
(-1.1)\end{array}$ & $\begin{array}{l}-0.0807 \\
(-0.51)\end{array}$ & $\begin{array}{l}-0.0826 \\
(-0.54)\end{array}$ & $\begin{array}{c}0.0371 \\
(0.05)\end{array}$ \\
\hline$\Delta G D P_{j m}$ & $\begin{array}{l}-0.2717 \\
(-0.29)\end{array}$ & $\begin{array}{l}-0.1643 \\
(-0.28)\end{array}$ & $\begin{array}{c}-15.6224 \\
(-1.53)\end{array}$ & $\begin{array}{c}0.2530 \\
(1.26)\end{array}$ & $\begin{array}{c}0.2366 \\
(1.21)\end{array}$ & $\begin{array}{l}-0.5235 \\
(-0.94)\end{array}$ \\
\hline Inflation $_{j m}$ & $\begin{array}{l}1.3826 \\
(1.48)\end{array}$ & $\begin{array}{l}-0.6164 \\
(-1.01)\end{array}$ & $\begin{array}{l}-7.5476 \\
(-0.05)\end{array}$ & $\begin{array}{c}-0.0271 \\
(-0.14)\end{array}$ & $\begin{array}{c}-0.0309 \\
(-0.16)\end{array}$ & $\begin{array}{l}-0.2532 \\
(-0.44)\end{array}$ \\
\hline$\Delta$ Noise $_{j m-1}$ & $\begin{array}{c}-8.001^{* * *} \\
(-8.00)\end{array}$ & $\begin{array}{c}-5.393^{* * *} \\
(-4.20)\end{array}$ & $\begin{array}{c}-1.6587^{* *} \\
(-2.52)\end{array}$ & $\begin{array}{c}-1.341^{* * *} \\
(-8.92)\end{array}$ & $\begin{array}{c}-1.330^{* * *} \\
(-8.83)\end{array}$ & $\begin{array}{c}-6.081^{* * *} \\
(-9.37)\end{array}$ \\
\hline$\Delta$ Noise $_{j m-2}$ & $\begin{array}{c}-3.995^{* * *} \\
(-3.50)\end{array}$ & $\begin{array}{c}-2.403^{* * *} \\
(-5.10)\end{array}$ & $\begin{array}{c}-0.1556 \\
(-0.31) \\
\end{array}$ & $\begin{array}{c}-1.090^{* * *} \\
(-6.25)\end{array}$ & $\begin{array}{c}-1.0791^{* * *} \\
(-6.16) \\
\end{array}$ & $\begin{array}{c}-3.409^{* * *} \\
(-4.59)\end{array}$ \\
\hline $\mathrm{R}^{2}$ & 0.3129 & 0.3377 & 0.2430 & 0.4401 & 0.4443 & 0.4366 \\
\hline Adjusted $R^{2}$ & 0.2366 & 0.2641 & 0.1589 & 0.3778 & 0.3826 & 0.3740 \\
\hline Observations & 111 & 111 & 111 & 111 & 111 & 111 \\
\hline
\end{tabular}




\section{IMPLICATIONS OF OUR FINDINGS}

The previous literature using price deviations in the yield curve as a measure of illiquidity mostly focuses on illiquidity conditions in the largest and highest rated sovereign bond markets of developed countries. We contribute to the existing literature by analyzing the ASEAN-5 sovereign markets, which are much smaller than the U.S. market (see Footnote 1). This aspect is very important for investors as bond liquidity is one of the major drivers of sovereign bond yields (Kinateder and Wagner, 2017). Our results show that illiquidity conditions between the ASEAN-5 sovereign bond markets are heterogeneous in many ways.

Firstly, illiquidity conditions in Singapore are closely related to those of the largest sovereign bond markets, such as the U.S. (Hu et al., 2013) and Japan (Hattori, 2019), implying a low liquidity risk exposure for investors during tranquil periods and significant risk premiums in a market-wide liquidity event (i.e. the global financial crisis). In addition, illiquidity in Singapore is driven by economic variables that were also found by previous studies (see e.g., Brunnermeier and Pedersen, 2009; Gilchrist et al., 2009; Nagel, 2012; Adrian et al., 2017). Secondly, noise in the remaining ASEAN-5 sovereign bond markets is significantly higher during tranquil periods compared to Singapore and arbitrage eliminates larger deviations not immediately but in a delayed manner, indicating that the risk exposure to liquidity is on average higher for investors and can hardly be anticipated by changes in economic drivers.

\section{CONCLUSION}

This paper examines illiquidity conditions during the period January 2008 to January 2019 in five ASEAN sovereign bond markets, namely Indonesia, Malaysia, the Philippines, Singapore, and Thailand, by exploiting price deviations in the yield curve, based on the noise measure introduced by $\mathrm{Hu}$ et al. (2013). The application of an innovative bond-specific noise measure to the ASEAN-5 sovereign bond markets distinguishes our work from earlier studies. Furthermore, we apply a multiple regression using a comprehensive set of explanatory variables in order to identify the drivers of illiquidity in the respective markets. Our results for Singapore show that the noise measure in this specific market is related to three economic drivers. The main driver is the corporate bond spread, as a proxy for the aggregate credit cycle, while at the same time an increase in economic policy uncertainty and declines in the aggregate business cycle, proxied by GDP growth rate, significantly drive sovereign bond illiquidity in Singapore. By studying two different sample periods, we find that our explanatory variables can explain illiquidity jumps in Singapore during a market-wide illiquidity event but not the fluctuation of noise on a very low level during tranquil periods. Our empirical results for Singapore also indicate that the noise measure does not only contain market-wide information, but also unique country-specific information, which is in line with the deliberations of Durham (2015). However, illiquidity of the remainder ASEAN-5 sovereign bond markets is mostly characterized by negative autocorrelation and not by economic drivers. The illiquidity in Indonesia, Malaysia, the Philippines, and Thailand might react in a delayed manner as markets have lower credit ratings and basic liquidity, which may reduce the 
number of international arbitrageurs. This possible explanation could be a topic for future research that may address this issue in more detail.

\section{ACKNOWLEDGMENTS}

We would like to thank two anonymous referees as well as Tonmoy Choudhury for helpful comments and discussions. All omissions and errors remain ours.

\section{REFERENCES}

Abduhl-Rahman, A., \& Sidek, N.Z. (2011). Spill-over Effect of US Sub-Prime Crisis on ASEAN-5 Stock Markets. International Review of Business Research Papers, 7, 1-11.

Acharya, V.V., \& Richardson, M.P. (2009). Causes of the Financial Crisis. Critical Review, 21, 195-210.

Adrian, T., Fleming, M., \& Vogt, E. (2017). An Index of Treasury Market Liquidity: 1991-2017 (Working Paper Federal Reserve Bank of New York Staff Reports no. 827). Federal Reserve Bank of New York.

Baker, S.R., Bloom, N., \& Davis, S.J. (2016). Measuring Economic Policy Uncertainty. Quarterly Journal of Economics, 131, 1593-1636.

Bao, J., Pan, J., \& Wang, J. (2011). The Illiquidity of Corporate Bonds. Journal of Finance, 66, 911-946.

Brunnermeier, M.K., \& Pedersen, L.H. (2009). Market Liquidity and Funding Liquidity. Review of Financial Studies, 22, 2201-2238.

Chung, K.H., \& Chuwonganant, C. (2018). Market Volatility and Stock Returns: The Role of Liquidity Providers. Journal of Financial Markets, 37, 17-34.

Davis, S.J. (2016). An Index of Global Economic Policy Uncertainty (NBER Working Paper Series No. 22740). National Bureau of Economic Research.

Duffie, D. (2010). Asset Price Dynamics with slow-moving Capital. Journal of Finance, 65, 1238-1268.

Durham, J.B. (2015). Speed and Conditional Noise as Information for Illiquidity and Fixed Income Arbitrage (SSRN Working Paper). SSRN.

Engle, R., Fleming, M., Ghysels, E., \& Nguyen, G. (2012). Liquidity, Volatility, and Flights to Safety in the U.S. Treasury Market: Evidence from a New Class of Dynamic Order Book models (Working Paper Federal Reserve Bond of New York Staff Reports No. 590). Federal Reserve Bond of New York.

Estrella, A., \& Hardouvelis, G.A. (1991). The Term Structure as a Predictor of Real Economic Activity. Journal of Finance, 46, 555-576.

Fama, E.F., \& French, K.R. (1989). Business Conditions and Expected Returns on Stocks and Bonds. Journal of Financial Economics, 25, 23-49.

Fleckenstein, M., Longstaff, F.A., \& Lustig, H. (2014). The TIPS-Treasury Bond Puzzle. Journal of Finance, 69, 2151-2197.

Gilchrist, S., Yankov, V., \& Zakrajsek, E. (2009). Credit Market Shocks and Economic Fluctuations: Evidence from Corporate Bond and Stock Markets. Journal of Monetary Economics, 56, 471-493. 
Goyenko, R., Subrahmanyam, A., \& Ukhov, A. (2011). The Term Structure of Bond Market Liquidity and Its Implications for Expected Bond Returns. Journal of Financial and Quantitative Analysis, 46, 111-139.

Gromb, D., \& Vayanos, D. (2002). Equilibrium and Welfare in Markets with Financially Constrained Arbitrageurs. Journal of Financial Economics, 66, 361407.

Hattori, T. (2019). Noise as Liquidity Measure in the Japanese Market: Evidence from Quantitative and Qualitative Easing by the Bank of Japan (SSRN Working Paper). University of Tokyo.

Helwege, J., Huang, J.Z., \& Wang, Y. (2014). Liquidity Effects in Corporate Bond Spreads. Journal of Banking and Finance, 45, 105-116.

$\mathrm{Hu}$, X., Pan, J., \& Wang, J. (2013). Noise as Information for Illiquidity. Journal of Finance, 68, 2341-2382.

Iyke, B.N. (2017). On the Term Structure of South African Interest Rates: Cointegration and Threshold Adjustment. International Journal of Sustainable Economy, 9, 300-321.

Kinateder, H., Hofstetter, B., \& Wagner, N. (2017). Do Liquidity Variables Improve Out-of-Sample Prediction of Sovereign Spreads during Crisis Periods? Finance Research Letters, 21, 144-150.

Kinateder, H., \& Wagner, N. (2017). Quantitative Easing and the Pricing of EMU Sovereign Debt. Quarterly Review of Economics and Finance, 66, 1-12.

Lapshin, V. (2019). A nonparametric Bayesian Approach to Term Structure Fitting. Studies in Economics and Finance, 36, 600-615.

Leland, H., \& Rubinstein, M. (1988). Comments on the Market Crash: Six Months after. Journal of Economic Perspectives, 2, 45-50.

Lim, L.K. (2009). Convergence and Interdependence between ASEAN-5 Stock Markets. Mathematics and Computers in Simulation, 79, 2957-2966.

Martell, R. (2008). Understanding Common Factors in Domestic and International Bond Spreads. Review of Finance, 12, 365-389.

Mitchell, M., \& Pulvino, T. (2012). Arbitrage Crashes and the Speed of Capital. Journal of Financial Economics, 104, 469-490.

Moinas, S., Nguyen, M., \& Valente, G. (2018). Funding Constraints and Market Illiquidity in the European Treasury Bond Market (Working Paper No. 21/2018). HKMIR Working Paper Series.

Musto, D., Nini, G., \& Schwarz, K. (2015). Notes on Bonds: Liquidity at all Costs in the Great Recession (SSRN Working Paper). University of Pennsylvania.

Nagel, S. (2012). Evaporating liquidity. Review of Financial Studies, 25, 2005-2039.

Newey,W.K., \&West,K.D.(1987).Asimplepositivesemi-definite, heteroskedasticity and autocorrelation consistent Covariance Matrix. Econometrica, 55, 703-708.

Nguyen, C., Bhatti, M.I., Komornikova, M., \& Komornik, J. (2016). Gold Price and Stock Markets Nexus under Mixed-Copulas. Economic Modelling, 58, 283-292.

Rudebusch, G.D., \& Williams, J.C. (2009). Forecasting Recessions: the Puzzle of the enduring Yield Curve. Journal of Business \& Economic Statistics, 27, 492-503.

Shleifer, A., \& Vishny, R. (1997). The Limits of Arbitrage. Journal of Finance, 52, 35-55.

Simon, D.P., \& Wiggins, R.A. (2001). S\&P Futures Returns and Contrary Sentiment Indicators. Journal of Futures Markets, 21, 447-462. 
Svensson, L.E.O. (1994). Estimating and Interpreting Forward Interest Rests: Sweden 1992-1994 (Working Paper No. 4871). NBER Working Paper Series.

Tripathi, A., Dixit, A., \& Vipul, V. (2020). Liquidity of Financial Markets: A Review. Studies in Economics and Finance, 37, 201-227.

Whaley, R.E. (2000). The Investor Fear Gauge. Journal of Portfolio Management, 26, 12-17.

Whaley, R.E. (2009). Understanding the VIX. Journal of Portfolio Management, 35, 98-105.

Ziaei, S.M. (2012). Effects of Gold Price on Equity, Bond and Domestic Credit: Evidence from ASEAN +3. Procedia - Social and Behavioral Sciences, 40, 341-346. 